\title{
Processing of convex complex surfaces with toroidal milling versus ball nose end mill
}

\author{
Andrei Oșan *, Mihai Bănică and Vasile Năsui \\ Technical University of Cluj-Napoca - North University Center of Baia Mare, Romania
}

\begin{abstract}
The paper aims to analyse the processing of convex complex surfaces with toroidal milling cutters compared to spherical milling cutters. As comparison terms, surface roughness and processing time are taken into account. The main purpose of the paper is to demonstrate the usefulness of the toroidal milling tool that can be replaced in case of spherical milling cuts to improve the working time as well as the surface quality, these terms playing an important role in the processing of convex complex surfaces.
\end{abstract}

\section{Introduction}

Complex and convex surfaces are encountered in many situations, such as aerospace, automotive, matrix, and pneumatic actuators. Surfaces are 3D generated using a CAD program, helping to describe geometry in order to generate the trajectory of the milling tool. [1]

The quality of the surface produced by milling depends on various technological parameters, such as cutting conditions, cutting geometry and workpiece specifications, as well as tool geometry selection. The basic parameters influencing the cutting geometry are: axial and radial depth, feed rate, tool speed, and tool positioning angle on the machined surface.

In the paper (Hayajneh et al., 2007) [2] are presented the effects of the parameters of the cutting process on the surface roughness. Factors such as the speed, feed, and depth of cutting that define the cutting process can be set in the initial phase, while factors such as tool geometry, tool wear, splintering, or tool material properties are uncontrollable (Huynh \& Fan, 1992 )[3].

Cosma M. [4] states that machining is characterized by a high degree of productivity, precision of form and dimension, universality and flexibility, encountering major difficulties, especially for complex geometric shapes, due to the high machining additions and due to the increased use of high resistivity materials, harsh and extraordinary which are difficult to scrape.

The processing of a curved surface can be done after a curve, or after a right, choosing the optimal variant in order to obtain the best surface quality was analysed in works such as (Hirogaki et al., 2007) [5] and (Schutzer \& Fagali, 2004) [6].

The processing of complex curved surfaces by milling with spherical head milling has been particularly striking in recent years due to the development of the $\mathrm{CNC}$ machine tool

* Corresponding author: osan.andrei@yahoo.com 
industry, CAD-CAM-CNC software development as well as new types of metal carbide tools Cosma, 2007) [7].

Paşca I. [8] argues that productivity machining operations spherical milling head is significantly effective when it is performed on CNC machine tools, which allow a high flexibility cutting conditions.

From the above analysis, it is clear that there is a need to conduct a comprehensive study to compare the two types of milling, based on the roughness of the surface. By default, once the surface quality has been compared, we can make an idea of the tool suitable for processing these complex surfaces for the time being, limiting them to 3-axis machining.

Bedi S. et. al [9] claims that toroidal cutters are increasingly used in mechanical machining of surfaces. The purpose of the paper is to compare the roughness of surfaces produced by spherical milling and toroidal milling. The comparison will be made in terms of roughness, parallel and perpendicular to the direction of the feed.

Jensen and Anderson [10] and Rao et al. [11] have shown that the machining of curved surfaces is not limited to the use of spherical and cylindrical frontal cutters, it is possible to use the toroidal cutter radius. Bull nose, toroidal milling or corner milling is a milling tool that improves productivity and reduces costs. In matrix processing, where spherical milling machines were typically used, toroidal cutters eliminate much more material and faster, improving productivity.

The productivity and the cost of processing are determined by the time consumed by performing various operations, which in turn depends on the technological variant applied and mainly on the cutting regimes used, which ultimately have the decisive role in reducing the overall production time of the product.

According to Sandvik Coromant [12], among the costs, about $20 \%$ is attributed to raw material, $10 \%$ overall, $5 \%$ to thermal treatment, and $65 \%$ to costs are attributed to processing. Optimization of machining operations is therefore fundamental when it is desired to reduce the cost of production of matrix or complex surfaces.

\section{Influence of cutting parameters on roughness}

It is necessary to specify from the outset that the concept of surface quality is related to the precision of the processing. Equally important is the notion of surface quality as another aspect of precision, namely what also includes its micro geometric aspect.

According to a previous paper [1], we have found that the best surface quality is obtained by processing in the advance direction due to the chip that is removed and no longer returns to the surface, as in the case of the advance processing.

It has been found that the parameter which most influences the surface roughness is the cutting speed. At lower speeds and higher speeds (over $50 \mathrm{~m} / \mathrm{min}$ ) due to lack of built-up edges roughness will decrease, and will be formed only traces of the tool.

According to an earlier paper [13], where optimal processing regimes of a complex surface have been experimentally deduced, it has been proven that with the increase of the speed and the advance the surface quality increases and at the same time decreases the processing time.

\section{Experimental status}

This paper aims to study the comparison between the milling head and the spherical toroidal in terms of roughness and in terms of productivity. 
To verify the results, we propose an experimental model with results analysed on 3 samples measured in the direction of the advance and 3 samples perpendicular to the advance. The comparison was made using two experimental tests.

\subsection{Practical experimental part}

For the practice was used a CNC machining centre MCV 1016 3-axis, manufacturing year 2015, from S.C. Ramira S.A.

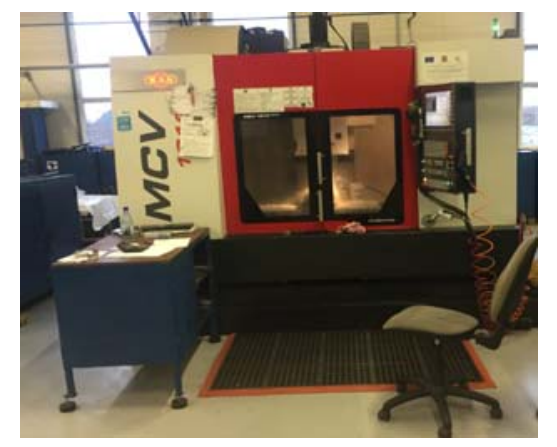

Fig. 1. CNC MCV 1016.

The two cutting tools used are: toroidal milling cutter JHP780160E2R400.0Z4-M64 and spherical head cutter JS534160D1B.0Z4-NXT.

The toroidal milling cutter or corner cutter has a diameter of $\varnothing 16$ with a maximum cutting depth of $32 \mathrm{~mm}$. Its corner radius is $4 \mathrm{~mm}$ having a number of 4 teeth.

The spherical cutter has a diameter of $\varnothing 16$, with a maximum cutting depth of $48 \mathrm{~mm}$. The corner radius is $8 \mathrm{~mm}$ having a number of 4 teeth.

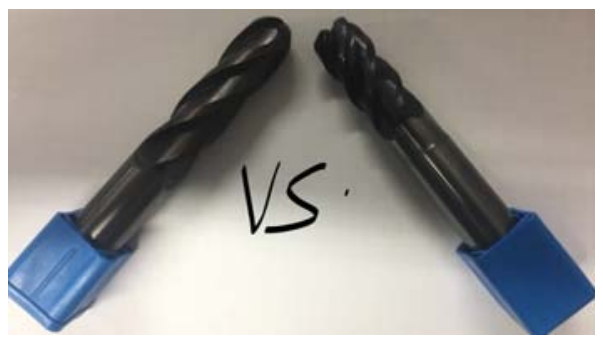

Fig. 2. Visual presentation of the two mills.

\subsection{The workpiece}

The piece has the shape of a square, being processed only one of the ends on which a complex surface is obtained, representing the active part of the piece. The material by used in the experiment is C45 (1.0503).

After analysing the material using a spectrometer it presents the following chemical components: Fe $98.6 \%$, C $0.463 \%$, Mn $0.556 \%$, Si $0.177 \%$, P $0.003 \%$, Cr $0.011 \%$, Mo $0.048 \%$, Ni $0.054 \%$, Al $0.258 \%$, Cu $0.01 \%$, Ti 0.013 , and so on, according to the analyses results that the material is $\mathrm{C} 45$. 


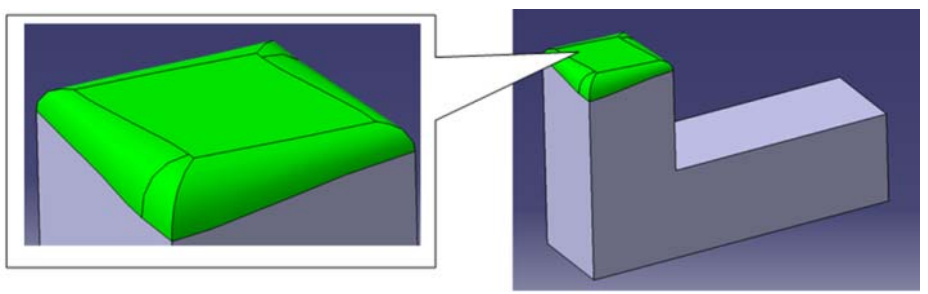

Fig. 3. The 3D representation of the landmark.

In order to achieve the tool path in both cases, both the milling processing with the toroidal surface and the spherical milling to the processing program has been generated using CAM software Powermill.

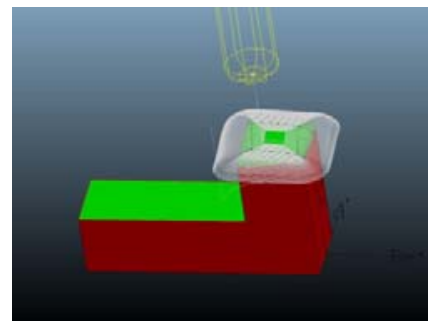

Fig. 4a The path of the toroidal milling tool.

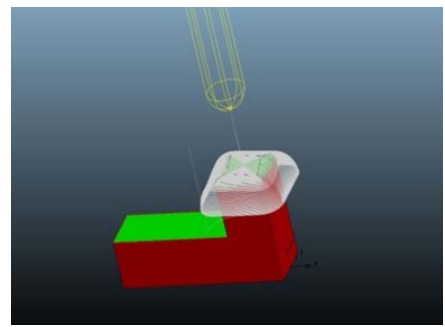

Fig. 4b The path of spherical milling tool.

For the piece made with spherical milling the speed and the advance proposed by the tool manufacturer were used, and for the part made using the toroidal milling, the regimes determined in a previous work were used.

The processing was performed with a $1 \mathrm{~mm}$ processing increment, having a $0.2 \mathrm{~mm}$ pitch, using coolant, these data being constant in both machining operations.
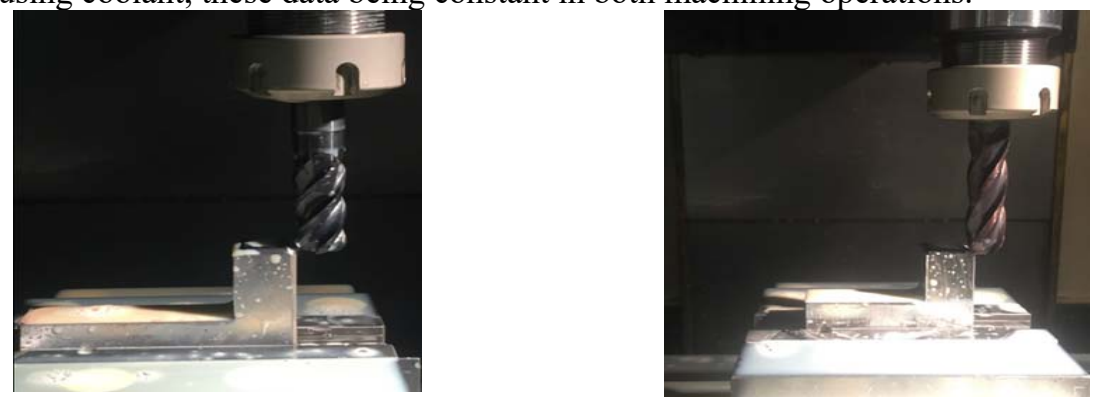

Fig. 5a Processing surface with toroidal milling.

Fig. 5b Processing surface with spherical milling.

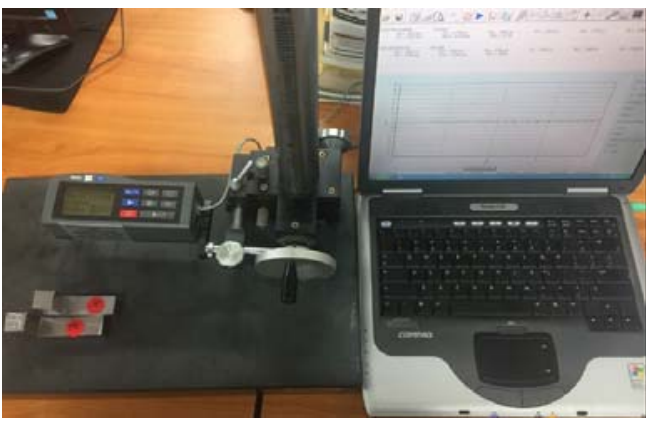

Fig. 6. Measure the roughness of the two surfaces. 


\subsection{Comparing of the roughness of the two processing surfaces with the toroidal and spherical milling}

The tool used to measure the roughness of the two surfaces is the TR 200 roughness, capable of measuring 13 roughness parameters and viewing the roughness profile, having an interface capable of hooking to a computer, the software being used as TimeSurf.

Table 1. Centralization of data measured.

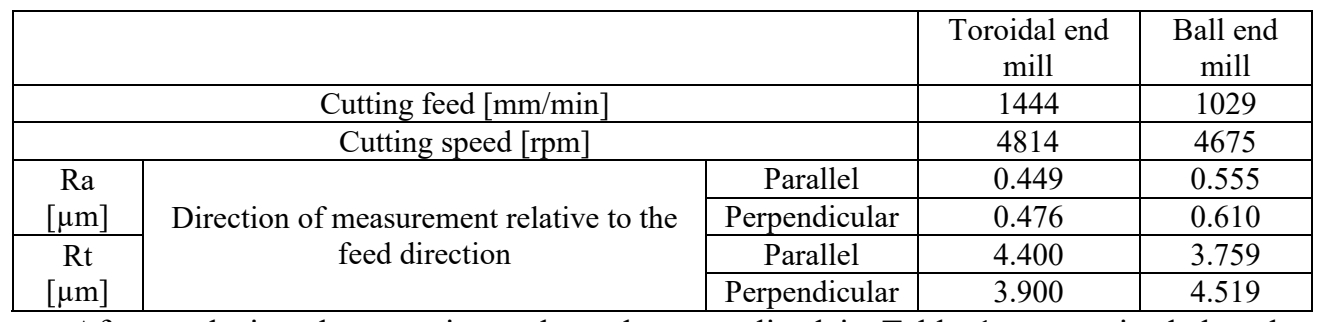

After analysing the experimental results centralized in Table 1, we noticed that the lowest values for $\mathrm{Ra}$ of $0.449 \mu \mathrm{m}$ were obtained after the toroidal milling process and the roughness measurement in the direction of the feed.

Analysing the vertical distance measurements, the highest and lowest values of the profile (Rt), it can be observed that the minimum value of $3.579 \mu \mathrm{m}$ is recorded by measuring the roughness in the direction of the advance of the surface with the spherical milling.

According to data extracted with the CAM program, the actual working time was observed in both cases, in the case of machining the complex surface with the toroidal milling, the working time is 4 minutes and 24 seconds, and in case of spherical milling with the same type of surface using the same type of material, the same processing addition and the same step, the actual working time is 9 minutes and 26 seconds.

\section{Experimental results}

According to the experiments carried out in this paper, comparisons between the two types of processing are presented in Table 2 .

Table 2. Experimental results.

\begin{tabular}{|c|c|c|}
\hline & $\begin{array}{c}\text { Toroidal end } \\
\text { mill }\end{array}$ & Ball end mill \\
\hline $\begin{array}{c}\text { Roughness Ra minim } \\
{[\mu \mathrm{m}]}\end{array}$ & 0.449 & 0.555 \\
\hline $\begin{array}{c}\text { Roughness Rt minim } \\
{[\mu \mathrm{m}]}\end{array}$ & 3.900 & 3.759 \\
\hline Material used & $\mathrm{C} 45(1.0503)$ & $\mathrm{C} 45(1.0503)$ \\
\hline Cutting feed [mm/min] & 1444 & 1029 \\
\hline Cutting speed [rpm] & 4814 & 4675 \\
\hline Cooling & Emulsion & Emulsion \\
\hline Work time $[\mathrm{min}]$ & $4: 24$ & $9: 26$ \\
\hline
\end{tabular}

\section{Conclusions}

The use of the toroidal cutter for complex and convex surfaces can be successfully applied due to the positive results it proves. 
Comparing the toroidal and spherical milling, there are no major differences in the roughness difference of $0.106[\mu \mathrm{m}]$ in favour of the toroidal milling in the case of the average roughness measurement $\mathrm{Ra}$ of $0.141[\mu \mathrm{m}]$ in the case of the Rt in favour of the spherical cutter.

If, from the point of view of surface quality, we can say that there are close values, from the point of view of productivity, of the working time there are much bigger differences, the surface processing with the toroidal milling being achieved by 5 minutes and 2 seconds faster, than spherical milling.

The experimental research carried out with the support of the processing department of S.C. Ramira S.A., Baia Mare.

\section{References}

1. A.R. Oșan, M. Cosma, V. Năsui, Milling convex surfaces with toroidal cutting edge, Innovative Ideas in Science, Banja Luka, Bosnia and Herzegovina (2017)

2. M.T. Hayajneh, M.S. Tahat and J.A. Bluhm, A study of the effects of machining parameters on the surface roughness in the end milling process, Jordan Journal of Mechanical and Industrial Engineering, 1, 1-5 (2007)

3. V.M. Huynh and Y. Fan. Surface texture measurement and characterization with applications to machine-tool monitoring. Intern. J. of Advanced Manufacturing Tehnology 7, 2-10 (1992)

4. M. Cosma. Milling with cylindrical-headed spherical cutters (in Romanian), Publishing House of North University Center of Baia Mare, România, 2010)

5. T. Hirogaki, A. Eiichi, M. Ryoji and S. Hidenori. Investigation of Ball Nose Endmilled Cylindrical Surface with a Scanning Line Cutter Path-Estimation of Influence of Ball Nose Accuracy Using a Makyoh-topography Image Method, Journal of the Japan Society for Precision Engineering. 73, 96-101, (2007)

6. K. Schutzer and S.A. Fagali. Interpolation Methods Analysis in High Speed Cutting of Free Form Surfaces, Ciencia \& Tecnologia, 11, 29-36, (2004)

7. M. Cosma. Horizontal Path Strategy for 3D-CAD Analysis of chip Area in 3Axes Ball Nose End Milling, 7th International Multidisciplinary Conference North University of Baia Mare, Scientific Buletin Serie C, Vol. XXI,(2007)

8. I. Pașca, Quality of surfaces at milling with spherical head cutters (in Romanian) $\mathrm{PhD}$ thesis, Technical University of Cluj-Napoca, North University Center of Baia Mare, România, 2013)

9. S. Bedi, F.Ismail, J. Mahjoob and Y. Chen. Toroidal Versus Ball nose and Flat Bottom End Mills. Int J Adv Manuf Technol Spinger-Verlag, London, (1997)

10. C.G. Jensen and D.C. Anderson, Accurate tool placement and orientation for finished surface machining. Journal of Design and Manufacture. 3 (1993)

11. N. Rao, S. Bedi and R. Buchal. Implementation of the principal axis method for machining of complex surfaces. International Journal of Advanced Manufacturing Technology, 11 249-257. (1996)

12. Manufacture of molds and dies-Application Guide, (Sandvik Coromant, 1999)

13. A. Oșan. Improving roughness using toroidal milling for complex surface processing. Magazine of Hydraulics, Pneumatics, Tribology, Ecology, Sensorics, Mechatronics (Hidraulica) 1 (2018) 